Studia Anglica Posnaniensia 52(2), 2017

doi: 10.1515/stap-2017-0007

\title{
REGIONAL VARIATION IN JESPERSEN'S CYCLE IN EARLY MIDDLE ENGLISH
}

\author{
GEORGE WALKDEN AND DONALD ALASDAIR MORRISON*
}

Department of Linguistics, University of Konstanz

Division of Linguistics and English Language, The University of Manchester

\begin{abstract}
In this paper we investigate the place of origin of the change from Jespersen's Cycle stage II - bipartite $n e+n o t-$ to stage III, not alone. We use the LAEME corpus to investigate the dialectal distribution in more detail, finding that the change must have begun in Northern and Eastern England. A strong effect of region and time period can be clearly observed, with certain linguistic factors also playing a role. We attribute the early onset of the change to contact with Scandinavian: North Germanic is known to have undergone Jespersen's Cycle earlier in its history, and the geographical distribution of early English stage III fits neatly with the earlier boundaries of the Danelaw.
\end{abstract}

Keywords: Middle English; negation; dialectology; language contact; corpus linguistics

\section{Introduction}

As is well known, English during its history has undergone the cyclical development that has since Dahl (1979) been known as Jespersen's Cycle. ${ }^{1}$ The

Authors' affiliations: George Walkden - Department of Linguistics, University of Konstanz, Fach 185, 78457 Konstanz, Germany, george.walkden@uni-konstanz.de; Donald Alasdair Morrison - Division of Linguistics and English Language, The University of Manchester, Oxford Road, Manchester M13 9PL, United Kingdom, donald.morrison@postgrad. manchester.ac.uk.

1 For comments and suggestions we would like to thank Ans van Kemenade, David Willis, Marcelle Cole, Anthony Warner, Sara Pons-Sanz, Wendell Kimper, and two anonymous reviewers for Studia Anglica Posnaniensia, as well as audiences at the Manchester Forum in Linguistics (MFiL) in 2014, the Symposium on the History of English Syntax (SHES) in Leiden in 2015, and the Angus McIntosh Centre (AMC) Symposium in Edinburgh in 2016. 
inherited Germanic preverbal negator $n i$ (later $n e$ ), as in (1), began to cooccur with forms of not (e.g., nawt, noht, na3t), as in (2), which could later occur alone as the sole clausal negator, as in (3). These examples show that all three stages of the cycle can be found during the Early Middle English period; in fact, all three examples are from the early fourteenth century. ${ }^{2}$

(1) swettore ping ne mizte be sweeter thing NEG might be 'there could be no sweeter thing' (Stage I; corp145selt.tag)

(2) he ne mai nozte loke tilward her lyzt he NEG may NEG look toward her light "he may not look toward her light" (Stage II; edincmct.tag)

$$
\begin{aligned}
& \text { for godd aght noght gif yam mercy } \\
& \text { for God ought NEG give them mercy } \\
& \text { "for God ought not to give them mercy" (Stage III; cotvespcmat.tag) }
\end{aligned}
$$

The English Jespersen's Cycle has been intensively studied since Jespersen (1917); Ingham (2013) provides an overview, with references, of this and other changes in the expression of negation in English. Important work on Middle English in particular has been carried out by Jack (1978); Iyeiri (1992, 2001); Frisch (1997); Laing (2002); Wallage (2005, 2008, 2013); Ingham (2006, 2008), among others.

In this paper we address a small, but important, part of the puzzle: where did the change from stage II, ne plus not, to stage III, not alone, begin? A previous quantitative study of Jespersen's Cycle, Wallage (2005, 2008), documented the chronological spread of stage III during the Middle English period in detail, but was not able to address this question, noting that the resource he was using, the Penn Parsed Corpus of Middle English (PPCME2; Kroch \& Taylor 2000), was not well balanced for dialect during the crucial period 1250-1350 CE (2005: 68, 205). Using a small hand-analysed corpus of late fourteenth- and fifteenthcentury prose texts, Ingham (2006: 90-91) was able to show that sentential negator $n e$ was used much less in Northern texts (4.4\%) than in Southern texts (17.2\%); however, in all texts except Chaucer's Boece retention of ne had already fallen below $30 \%$, suggesting that the real action took place somewhat earlier.

The empirical work for this project was funded by a Q-Step summer internship at the University of Manchester.

2 Example references are to files in the Linguistic Atlas of Early Middle English (Laing 2013-). 
The availability of the Linguistic Atlas of Early Middle English (Laing 2013-) makes it possible to fill this gap in the literature, and that is what this paper aims to do. In section 2 we outline our data sources and methodology for data collection and analysis; the results are presented in section 3. As already noted by Ingham (2008: 133) on the basis of his later data, the geographical asymmetry between the north and east on the one hand and the south and west on the other are suggestive of a Scandinavian origin for stage III, or at least a catalysing effect, and we devote some time to discussion of these possibilities in section 4. Section 5 then summarizes and concludes.

\section{Methodology}

\subsection{LAEME}

The data source we make use of is the Linguistic Atlas of Early Middle English corpus (Laing 2013-; henceforth LAEME), version 3.2. LAEME is a sister project to the Linguistic Atlas of Late Medieval English (LALME; McIntosh et al. 1986), and covers the precise time period that is of interest to us, 1150-1350. The corpus is freely available online and contains nearly 650,000 lexicogrammatically tagged words, based on diplomatic transcriptions of original manuscript sources rather than editions. This corpus represents nearly all the Early Middle English that has been passed down to us, though some extensive texts are sampled rather than included in their entirety.

Importantly for our purposes, the LAEME texts are all dated, and most are localized (more or less approximately) using a six-figure National Grid reference. These features enable the spread of changes to be tracked quite precisely through time and space, at least as far as the extant sources allow, as amply demonstrated by the case studies in Studer-Joho (2014).

LAEME dates are often provided as ranges rather than points (e.g., last quarter of the thirteenth century). Since the graphical and statistical methods we use require points, we have converted these ranges into points, either using a more precise year suggestion if one is provided or by simply taking the midpoint of the range. Thus, for example, last quarter of the thirteenth century is taken as 1288 if no more precise dating is provided. For a full list of dates chosen, see the Appendix. It must be kept in mind that the apparently precise nature of these dates (like the grid references) in fact masks a great deal of uncertainty.

For the basic statistics where a single independent variable is under investigation, we have used the standard two-tailed $\chi^{2}$ test with a threshold of $p=$ 0.05 to determine significance, along with Cramér's $V$ as a measure of effect size. This is a useful addition because some of the effects that emerge as significant in a $\chi^{2}$ test may be very weak indeed. An effect size of 0.1 is considered weak, 0.3 medium, and 0.5 large. 


\subsection{Data collection}

Tokens of stages I, II, and III were counted in each text contained in the LAEME corpus. For the most part, this task was automated using the lexicogrammatical tagging system featured in the corpus, so some tagging errors may have been carried through into our data. Inspection of portions of the corpus suggested that such errors were extremely rare, and the one or two that were encountered were corrected manually. It is not believed that enough errors could be present in the data to affect our results in any meaningful way.

What follows is an overview of the criteria used in the classification of different types of negation; for more detailed discussion of the constructions that occur in the corpus and the difficulties in analysis that may be encountered see Laing \& Lass (2008- Chapter 4, 53ff.).

\subsubsection{Clausal and constituent negation}

For the purposes of this study we are interested only in tokens of clausal negation, i.e., when negation syntactically carries scope over an entire clause as in (1)-(3) above. We do not consider constituent negation by means of other negative items such as negative pronouns (nobody, nothing), negative adverbs (never, nowhere), negative quantifiers (no), etc.; also excluded are tokens of not which can only be analysed as negating a single constituent rather than an entire clause. This is due to the fact that although constituent negation in Old English was normally accompanied by ne placed in front of the finite verb, thereby bearing at least a superficial resemblance to clausal negation, its subsequent development differs greatly as a result of Jack's Law (Jack 1978: 299). Jack's Law states that

\footnotetext{
ne ... nawt [stage II] is not normally used in clauses containing other negative forms [...]. The group of negative forms normally incompatible with ne ... nawt does not, however, include the conjunction ne 'nor', for ne ... nawt is freely used in clauses introduced by or containing this conjunction [...].
}

The presence of other negative items such as pronouns, adverbs, or quantifiers thus interferes with the ordinary operation of Jespersen's Cycle by preventing the occurrence of stage II, and constituent negation is therefore not of interest to us here. However, because stage II may occur in clauses introduced by or containing the negative conjunction 'nor', we do count (separately) tokens of negation appearing in such contexts. Negation in 'nor' contexts will be discussed in more detail below.

We also ignore the construction ne ... but meaning 'only', with which stage II negation is very rare. 


\subsubsection{Minor types}

In addition to the three main types $n e+$ verb, $n e+$ verb + not and verb $+n o t$, a handful of infrequent minor types occur in the corpus. These result from either the duplication of $n e$ in stage I or II constructions (4), or the placing of not before the verb instead of after it in stage II or III constructions (5). Note that we follow LAEME in recognizing double $n e$ only when it is impossible to analyse the first instance of $n e$ as the conjunction 'nor' (see below).

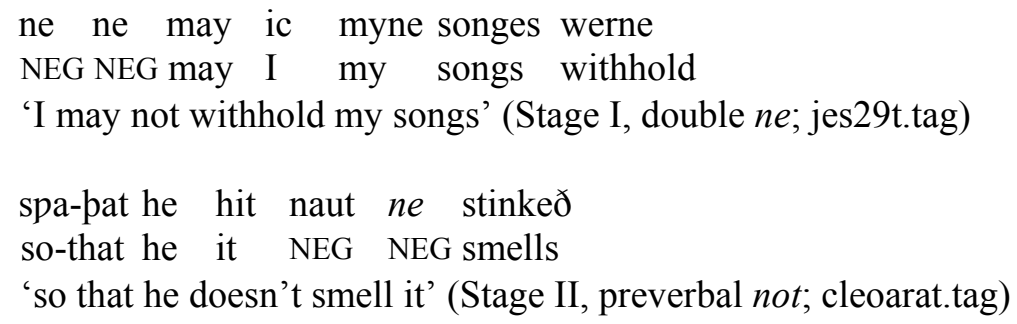

We consider the relevant criteria for identifying stage I, II, and III negation to be the presence or absence of $n e$ and/or not, without regard to whether ne is duplicated or not is positioned before the verb. Examples such as those in (4) and (5) are therefore assigned to stages I, II, or III accordingly.

\subsubsection{Contracted forms}

In stage I and stage II negation the negative particle ne may contract with the following verb under certain lexical and phonological conditions, as shown in (6). Specifically, this can occur with a handful of verbs in initial vowel, $/ \mathrm{h} /$, or $/ \mathrm{w} /$ primarily have, will, witan ('know'), and some forms of be.

$$
\begin{aligned}
& \text { hy nuste ware hy were } \\
& \text { they NEG.knew where they were } \\
& \text { 'they didn't know where they were' } \\
& \text { (Stage I, contracted; corp145selt.tag) }
\end{aligned}
$$

Contraction has been shown to be dialectally variable in Old and Middle English (Levin 1958, Hogg 2004, Iyeiri 1992, 2001, Van Bergen 2008), with West Saxon Old English and Southern and West Midlands Middle English exhibiting contraction much more regularly. If contraction were a purely phonological (or orthographic) phenomenon, there would be no particular reason to expect contracted forms to behave any differently from other instances of ne syntactically. In later English, however, when ne has otherwise disappeared 
entirely, it is retained with some verbs on a lexically specific and constructionspecific basis, e.g., nill 'not want' in the set phrase will you, nill you (as in Shakespeare's Taming of the Shrew). This suggests that in some instances the contracted negative particle has been reanalysed as part of the verb, creating a new lexical verb with inherently negative meaning. If this is the case already in Early Middle English, we might expect contracted forms to have a different distribution to non-contracted forms. We therefore count contracted tokens of stages I and II separately from uncontracted tokens, and discuss the results in section 3.3.1.

\subsubsection{Contexts with 'nor'}

The negative conjunction 'nor' may appear either inside or outside the scope of negation. When it appears inside the scope of negation, it links two or more constituents in the clause (7). When it appears outside the scope of negation, it links two or more negative clauses (8).

(7) bou ne sselt do ine pe daye of be sabat pine nyedes ne pine you NEG shall do on the day of the Sabbath your duties nor your works

works

'you shall not do your duties nor your work on the day of the Sabbath'

(Stage I, constituent nor; ayenbitet.tag)

(8)

$$
\text { ðe ne pile ne ne mai godes lare understanden }
$$

that NEG wants nor NEG may God's teaching understand

'that doesn't want to understand, nor may understand, God's teaching'

( 2 x stage I, linked by clausal nor; vvat.tag)

According to Jack's Law, the presence of 'nor', unlike other negative words, does not prevent the occurrence of all three stages of Jespersen's Cycle. In order to find out whether 'nor' has any effect at all, we count tokens of clausal negation in such environments separately, and discuss the results in section 3.3.2. An added complication arises in constructions such as that in (9), in which the second (or later) of two (or more) constituents linked by 'nor' contains a negative item such as a negative quantifier. In spite of the fact that this negative item is within the scope of the negation, 'not' may freely occur here. Such constructions are not counted here. 
(9) \& na magen noht itimien par-of to eten ne to drinken ne na and NEG may NEG happen thereof to eat nor to drink nor no god don per-of good do thereof 'and may not happen to eat or drink thereof nor do any good thereof' (lamhomA1t.tag)

For simplicity, we ignore the rare instances of a negative clause linked by 'nor' to a preceding positive clause, as in (10).

(10) 3if hit folhes hire her ne ne drahes hire to spiðe into hire lahe if it follows it here nor NEG draws it too much into its low cunde

kind

'if it follows it here and doesn't draw it too much into its low kind' (titusart.tag)

Due to the fact that the preverbal negative particle, the negative conjunction 'nor', and even the negative adverb 'neither' are very often identical in form, all being written $n e$, ambiguity may arise in certain constructions. In (11) the second ne, here glossed simply as NE, appears to simultaneously function both as a conjunction 'nor' and as the marker of negation in the second clause. In (12) the first ne may be read as both 'neither' and as the negator of sien, and the second as both 'nor' and the negator of understande. Since such ambiguity makes classification impossible, all constructions of this kind are ignored.

(11) a tord ne yeue ic for eu alle, ne schal ar hit beo fullich a turd NEG give I for you all, NE shall before it be fully eve a wrecche vepere on eu bileue evening a wretched feather on you remain 'I don't give a shit for all of you, nor shall a wretched feather remain on you by evening'

OR 'I don't give a shit for all of you. Not a wretched feather shall remain on you by evening' (jes29t.tag)

(12) pat hie ne sien ne understande that they NE see NE understand 'so that they may neither see nor understand' (vvbt.tag) 


\section{Results}

The results in this section are taken from texts that meet three criteria: a) they are datable, b) they are localizable, and c) they contain tokens of the variable in question. There are 74 such texts in total; the full breakdown by text can be found in the appendix. Except where otherwise stated, examples containing contracted forms of ne (as in example (6) above) are excluded from the analysis, as are examples containing nor (see section 3.3.).

\subsection{Chronological overview}

Table 1 divides the data into four fifty-year periods. We can see from this that before 1250 the stage III variant we are most interested in is virtually unattested.

Table 1: Number and percentage of each stage by period

\begin{tabular}{l|c|c|c|c|r|r|r}
\hline Period & \multicolumn{2}{|c|}{ Stage I } & \multicolumn{2}{l|}{ Stage II } & \multicolumn{2}{l|}{ Stage III } & Total \\
\hline & $\mathrm{N}$ & $\%$ & $\mathrm{~N}$ & $\%$ & $\mathrm{~N}$ & $\%$ & $\mathrm{~N}$ \\
\hline $1150-1199$ & 102 & 59.0 & 68 & 39.3 & 3 & 1.7 & 173 \\
\hline $1200-1249$ & 430 & 55.9 & 330 & 42.9 & 9 & 1.2 & 769 \\
\hline $1250-1299$ & 265 & 60.0 & 153 & 34.6 & 24 & 5.4 & 442 \\
\hline $1300-1350$ & 244 & 32.1 & 279 & 36.7 & 238 & 31.3 & 761 \\
\hline
\end{tabular}

Figure 1 (next page) presents a more nuanced picture, with each text plotted separately. In this figure, the size of the points represents the number of examples, and the line is a smoothed conditional mean calculated using loess.

It appears that stage I is on the increase whereas stage III is on the decrease at the start of the period, around 1150-1175, but almost nothing can be concluded from the minuscule numbers of examples here, and the confidence intervals are very large. Between 1175 and 1275 it appears that little is changing, but after 1275 stage III gains ground at the expense of the earlier stages, so that by the end of the period it seems to be the majority form. This simple picture masks considerable regional variation, however, to which we now turn.

\subsection{Geographical overview}

Figure 2 gives a geographical overview of all usable texts from the LAEME corpus. The area of each point is scaled to represent the number of tokens in that text or hand; the darker the shade, the higher the percentage of stage III of Jespersen's Cycle. 


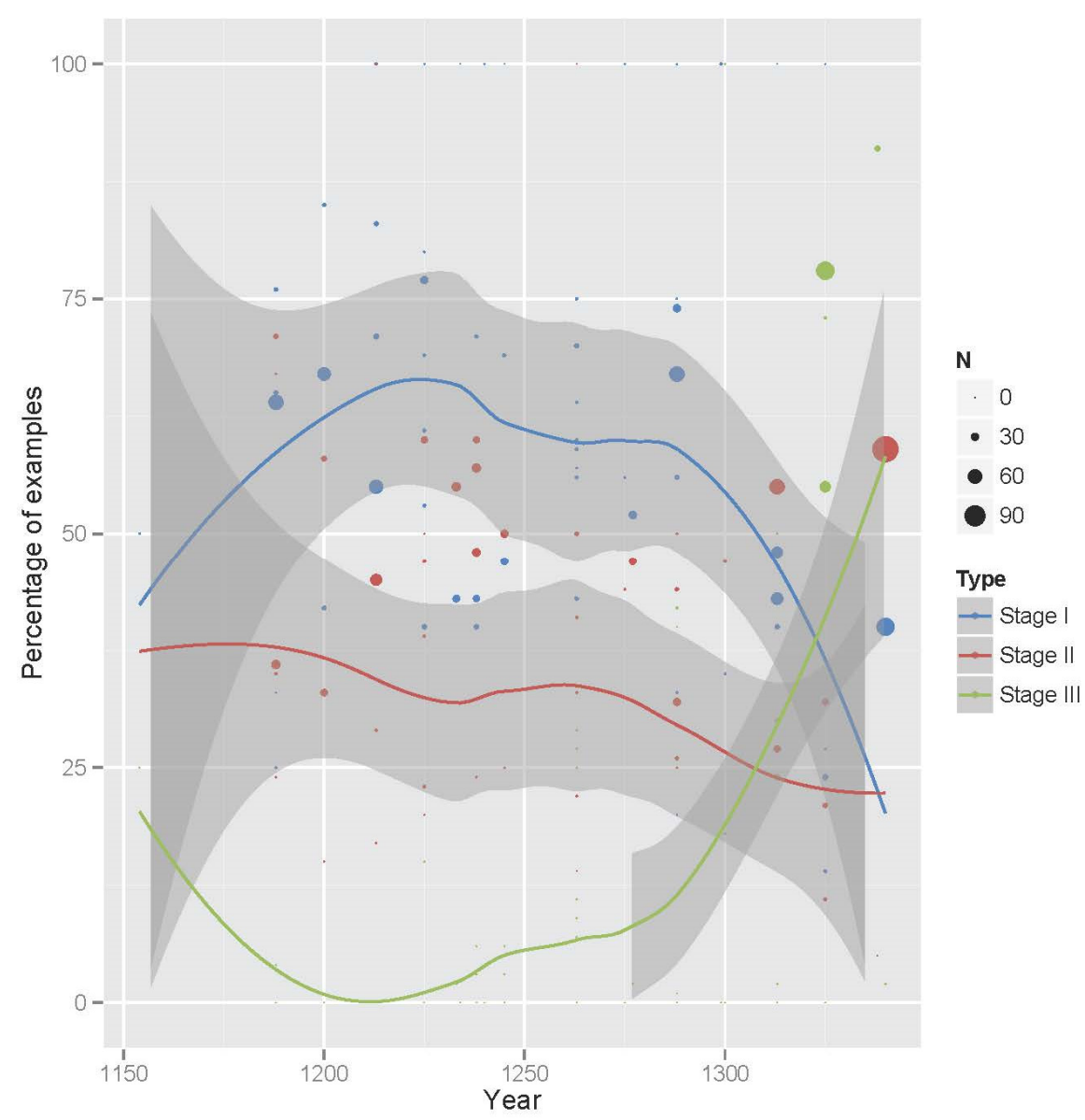

Figure 1. Number and percentage of each stage by year of text

The overall pattern is very clear: in the Early Middle English period, stage III is found first, and most often, in texts from the north and east. Figures $3 \mathrm{a}-3 \mathrm{~d}$ on page 183 break this down by time period. In these maps, the points are once again scaled by the number of tokens, but this time they are pie charts: blue is stage I, red is stage II, and green is stage III. The insets in $3 b$ and $3 c$ zoom in on the West Midlands area around Hereford, Gloucester, and Worcester, where many of the manuscripts from this century originate. Stage III is virtually unattested before 1250 , and starts to occur as the majority option only in northern and eastern texts after 1300. Crucially, it is not until this last subperiod that we have texts of any size from the area north of the Wash and east of the Pennines. 
A possible bias towards stage III in the north and east is mentioned by Iyeiri (1992: 78-85), though on the basis of less material, and exclusively verse. Ingham (2006), too, finds that $n e$ is omitted more frequently in northern than in southern Late Middle English prose.



Figure 2. Overview of percentage use of stage III

\subsection{Linguistic factors}

Many linguistic factors have been shown to influence the progress of Jespersen's Cycle in English: see Iyeiri (1992, 2001); Wallage (2005, 2008, 2013) for overviews. Since our focus here is on the external factors of time and place, we included here only those factors that we thought might skew the overall picture. Future investigation of the precise linguistic factors conditioning the expression of negation in the Early Middle English data is likely to be a fruitful endeavour. 


\subsubsection{Contraction}

As seen in example (6) above, and discussed in section 2.2.3., the negative particle ne may contract with the following verb under certain lexical and phonological conditions. This possibility varies by dialect in Old and Middle English (Levin 1958, Hogg 2004, Iyeiri 1992, 2001, Van Bergen 2008), with West Saxon Old English and Southern and West Midlands Middle English exhibiting contraction much more regularly. As discussed above, if the contracted negative particle has been reanalysed as part of the verb, creating

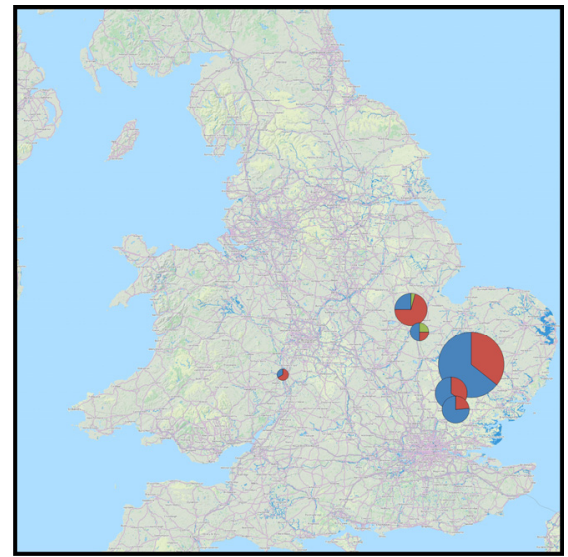

(a) Jespersen's Cycle 1150-1199



(c) Jespersen's Cycle 1250-1299

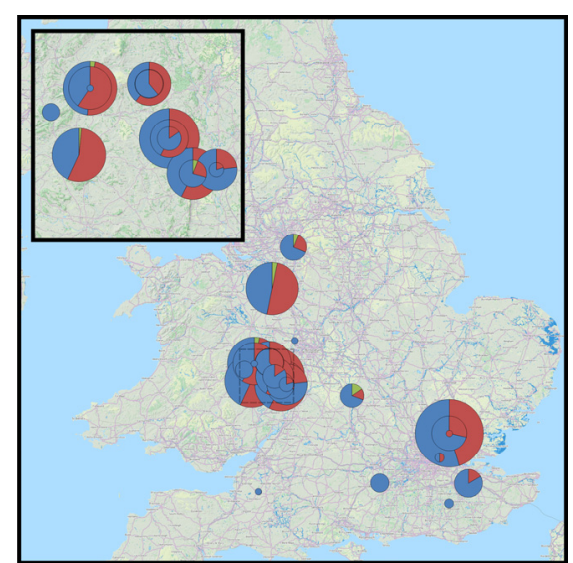

(b) Jespersen's Cycle 1200-1249

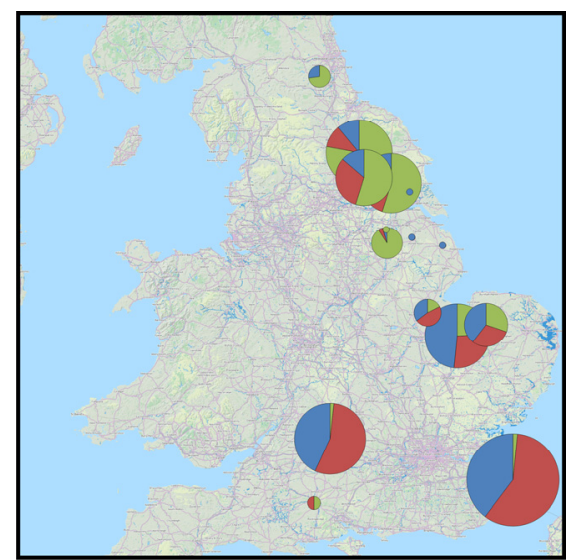

(d) Jespersen's Cycle 1300-1350

Figure 3: Jespersen's Cycle in Early Middle English by subperiod 
a new verb with inherently negative meaning, we might expect contracted forms to have a different distribution to non-contracted forms. Inspection of the trajectory of the change with contracted forms included alongside uncontracted forms suggests that any such effect is minimal, however: compare figure 4 with 1 above. This is despite the fact that contracted forms occur with substantial frequency. ${ }^{3}$



Figure 4: Number and percentage of each stage by year of text (contracted forms included)

3 Contracted stage I forms were also found in five texts that were not included in the main study (appendix A) because they did not display examples of uncontracted negation. These are winchestert.tag and ramseyat.tag ( 2 examples each) as well as wellsat.tag, ramseycott.tag, and swinfieldt.tag ( 1 example each). These examples are not included in tables $2-5$ or figure 4 , but would not change the overall results if included. 
The distribution of contracted and non-contracted forms across stage I and stage II also suggests that there is little or no grammaticalization effect at this early stage. Though there is a statistically significant effect for the three periods after 1200 at the $p<0.05$ level, with contracted forms more likely to occur without not, the effect size (Cramér's V) is very small in all cases. Outside this section we have excluded contracted forms to be on the safe side, but the evidence in this section suggests that the picture would not be very different if they were included.

Table 2. Uncontracted vs. contracted, 1150-1199

$\left(p=0.6596 ; \chi^{2}=29.493 ; d f=1\right)$

\begin{tabular}{l|c|c|c|c}
\hline \multicolumn{2}{r|}{ Stage I N } & $\%$ & Stage II N & $\%$ \\
\hline Uncontracted & 102 & $60.0 \%$ & 68 & $40.0 \%$ \\
\hline Contracted & 28 & $63.6 \%$ & 16 & $36.4 \%$ \\
\hline
\end{tabular}

Table 3. Uncontracted vs. contracted, 1200-1249

$\left(p=0.0447 ; \chi^{2}=4.031 ; d f=1 ; V=0.0595\right)$

\begin{tabular}{l|c|c|c|c}
\hline \multicolumn{2}{r|}{ Stage I N } & $\%$ & Stage II N & $\%$ \\
\hline Uncontracted & 430 & $56.6 \%$ & 330 & $43.4 \%$ \\
\hline Contracted & 238 & $62.8 \%$ & 141 & $37.2 \%$ \\
\hline
\end{tabular}

Table 4. Uncontracted vs. contracted, 1250-1299

$\left(p=0.0019 ; \chi^{2}=9.664 ; d f=1 ; V=0.1128\right)$

\begin{tabular}{l|c|c|c|c}
\hline \multicolumn{2}{l|}{ Stage I N } & $\%$ & Stage II N & $\%$ \\
\hline Uncontracted & 265 & $63.4 \%$ & 153 & $36.6 \%$ \\
\hline Contracted & 243 & $74.1 \%$ & 85 & $25.9 \%$ \\
\hline
\end{tabular}

Table 5. Uncontracted vs. contracted, 1300-1350

$\left(p=0.0134 ; \chi^{2}=6.115 ; d f=1 ; V=0.0975\right)$

\begin{tabular}{l|c|c|c|c}
\hline \multicolumn{2}{r|}{ Stage I N } & $\%$ & Stage II N & $\%$ \\
\hline Uncontracted & 244 & $46.7 \%$ & 279 & $53.3 \%$ \\
\hline Contracted & 71 & $59.2 \%$ & 49 & $40.8 \%$ \\
\hline
\end{tabular}

3.3.2. Jack's Law: The influence of 'nor'

In a pioneering study of the English Jespersen's Cycle in Late Middle English prose, Jack (1978: 299) observes that Stage II is not typically used in clauses that contain other negative forms, but suggests that the conjunction ne 'nor' does not count, as Stage II is 'freely used' in clauses with this conjunction. The latter part 
of this claim can be assessed quantitatively on the basis of the LAEME data. What emerges is that, although Jack's Law holds as an existential claim (ne 'nor' is attested alongside all three stages), the presence of 'nor' seems to disfavour the presence of not: stage I is significantly more common, and stages II and III significantly less common, in clauses introduced by or containing 'nor'.

Table 6. With vs. without 'nor', 1150-1199

\begin{tabular}{c|c|c|c|c|c|c}
\hline \multicolumn{3}{c|}{ Stage I N } & $\%$ & Stage II N & $\%$ & $\begin{array}{l}\text { Stage III } \\
\text { N }\end{array}$ \\
\hline $\begin{array}{l}\text { Without } \\
\text { 'nor' }\end{array}$ & 102 & $59.0 \%$ & 68 & $39.3 \%$ & 3 & $1.7 \%$ \\
\hline $\begin{array}{l}\text { With } \\
\text { 'nor' }\end{array}$ & 33 & $73.3 \%$ & 11 & $24.4 \%$ & 1 & $2.2 \%$ \\
\hline
\end{tabular}

Table 7. With vs. without 'nor', 1200-1249

$\left(p=0.0002 ; \chi^{2}=17.383 ; d f=2 ; V=0.1372\right)$

\begin{tabular}{|c|c|c|c|c|c|c|}
\hline \multicolumn{2}{|c|}{ Stage I N } & $\%$ & Stage II N & $\%$ & Stage III N & $\%$ \\
\hline $\begin{array}{l}\text { Without } \\
\text { 'nor' }\end{array}$ & 430 & $55.9 \%$ & 330 & $42.9 \%$ & 9 & $1.2 \%$ \\
\hline $\begin{array}{l}\text { With } \\
\text { 'nor' }\end{array}$ & 121 & $73.3 \%$ & 42 & $25.5 \%$ & 2 & $1.2 \%$ \\
\hline
\end{tabular}

Table 8. With vs. without 'nor', 1250-1299

$\left(p=0.0016 ; \chi^{2}=12.874 ; d f=2 ; V=0.1628\right)$

\begin{tabular}{|c|c|c|c|c|c|c|}
\hline \multicolumn{2}{|c|}{ Stage I N } & $\%$ & Stage II N & $\%$ & Stage III N & $\%$ \\
\hline $\begin{array}{l}\text { Without } \\
\text { 'nor' }\end{array}$ & 265 & $60.0 \%$ & 153 & $34.6 \%$ & 24 & $5.4 \%$ \\
\hline $\begin{array}{l}\text { With } \\
\text { 'nor' }\end{array}$ & 58 & $81.7 \%$ & 10 & $14.1 \%$ & 3 & $4.2 \%$ \\
\hline
\end{tabular}

Table 9. With vs. without 'nor', $1300-1350$

$\left(p<0.0001 ; \chi^{2}=36.228 ; d f=2 ; V=0.2463\right)$

\begin{tabular}{l|c|c|c|c|c|c}
\hline \multicolumn{2}{c|}{ Stage I N } & $\%$ & Stage II N & $\%$ & Stage III N & $\%$ \\
\hline $\begin{array}{l}\text { Without } \\
\text { 'nor' }\end{array}$ & 244 & $32.1 \%$ & 279 & $36.7 \%$ & 238 & $31.3 \%$ \\
\hline $\begin{array}{l}\text { With } \\
\text { 'nor' }\end{array}$ & 55 & $64.7 \%$ & 19 & $22.3 \%$ & 11 & $12.9 \%$ \\
\hline
\end{tabular}


For the earliest period some of the cells are too small for a $\chi^{2}$ test to be meaningful, but there is a clear significant effect for the other three periods. The effect is larger than the effect of contraction, but still not particularly large: a Cramér's $V$ of 0.3 indicates a medium-sized effect, and none of the periods comes close to that.

It is not clear what causes this effect, which to our knowledge has not been observed before. Wallage (2013) demonstrates that the alternation between stage I and stage II in Middle English is sensitive to pragmatics: stage I is more likely in clauses expressing discourse-new propositions, while stage II is more likely in clauses expressing discourse-old propositions. If clauses introduced by 'nor' are more likely to be discourse-new than other clauses, then the discourse status of the proposition could be a lurking variable that explains the subtle difference here. However, independent evidence would be needed to confirm or deny this.

\section{Scandinavian influence?}

The results in the previous section show a striking geographical pattern: stage III appears sooner, and with greater frequency, in the north and east than in the south and west. One possibility is that this is due to contact between these varieties of Middle English and Scandinavian. Figure 5 gives an approximate overview of the Danelaw during the Anglo-Norman period, based on the discussion in Holman (2001: 4-7). Comparing this to the distribution of stage III in Figures 3a-3d is highly suggestive. See also the map of Scandinavian place-names in Sawyer (1971: 161), which provides a more likely indication of the areas actually settled by Scandinavians during the ninth century.

This is not a new claim: Ingham (2008) has suggested, on the basis of later Middle English data from the late 14th and 15th centuries, that Scandinavian contact caused the shift to stage III of Jespersen's Cycle. Nevertheless, since the Anglo-Scandinavian language contact situation has been the subject of vigorous debate, we find it important to lay out our reasoning in detail. In subsection 4.1. we discuss the general contact situation, and in subsection 4.2. we return to the specifics of the loss of $n e$.

\subsection{Norse and early English in contact}

Evaluating any claim of Scandinavian influence on English is tricky, since virtually every conceivable position has been espoused by at least one linguist in the last forty years. Points of dispute include at least i) the stratal, prestige, and power relations between Norse and English speakers, ii) the size of the Norse-speaking population of England, and iii) the type and intensity of contact involved. ${ }^{4}$

$4 \quad$ We will take it as given, following Thomason \& Kaufman (1988, section 9.8) and most 
With regard to i), the most common assumption is that Norse and English were roughly adstratal in medieval England, with little if any difference in prestige (Hock 1986: 410, Townend 2002: 204, Trudgill 2011: 53). Thomason \& Kaufman (1988: 303), however, suggest that "Norse influence on English was a kind of prestige borrowing that took relatively little effort to implement", and more recently Lutz (2012) has argued that Norse was consistently in a superstratal relationship with English. What this approach fails to explain is the two distinct waves of Norse lexical transfer into English. The first, which is already evident in Old English texts, primarily affected the specific domains of administrative, seafaring, and legal vocabulary (Peters 1981, Kastovsky 2006: 223, Pons-Sanz 2007, 2013). This type of borrowing is consistent with a prestige-based or superstrate-based explanation, though some might also have been catalysed by 'need', new technologies or concepts rather than prestige or superstratal status per se. The second wave, whose effects are not seen until Middle English, is much broader, and extends to very basic vocabulary items, e.g., egg, red, give. Lutz is aware of these two waves, but her suggestion that the latter, too, are borrowings resulting from the superstratal status of Old Norse is not entirely convincing. If Norse served the role of superstrate throughout its time in the British Isles, why would there have been two qualitatively different waves of lexical influence? It seems more likely that Norse only initially served as superstrate within the Danelaw, if at all, but that during the Early Middle English period this gave way to an adstratal relationship (cf. Miller 2012: 97). In support of this perspective, Townend (2002: 201-207) points out that early Norse loans tend to be phonologically assimilated into Old English, whereas later loans retain their Norse phonology - mysterious again if both represent the same kind of transfer from the superstrate. ${ }^{5}$

subsequent literature, that there is continuity between Old and Modern English, i.e., that Middle English is neither a creole (as suggested by Poussa 1982) nor a direct descendant of Norse (as suggested by Emonds \& Faarlund 2014). We refer the reader to Görlach (1986) and Mitchell (1994: 163-170) for arguments against the creole theory, and to Bech \& Walkden (2016) for arguments against the Anglicized Norse theory.

5 Lutz (2012: 27, fn. 34) takes Hock (1986) to task for "erroneously" stating that adstratal relationships are most conducive to borrowing of basic vocabulary (see also Lutz 2013), but does not provide evidence or argumentation against such a statement. 




Figure 5. The approximate extent of the Danelaw circa 1100, based on Holman (2001: 4-7)

As for ii), Thomason \& Kaufman (1988: 282) assume that there were only ever "a modest number of Norse-speaking settlers", forming "a relatively small percentage" of the population (1988: 299). This assumption is based on the data and argumentation in Sawyer (1971), whose main thesis is that the scale of Norse migration to Britain has been greatly exaggerated. Sawyer's point that the AngloSaxon texts cannot be taken at face value, written as they were by churchmen who had every reason to overplay the numbers of Norsemen involved, is an important one; nevertheless, more recent philological, archaeological, and historical research has tended to corroborate the traditional assumption of a reasonable-sized wave of settlement, or at least to suggest that Sawyer's estimates were on the low side (see Loyn 1977, Brooks 1979, Hadley 1997). Genetic 
evidence does not yet resolve the question. While there is evidence from mitochondrial DNA that Viking females were more prevalent in the north and east (Sykes 2006: 324-325), as well as a "huge difference" in Y-DNA between the north-east and the south-west, in a recent survey article, Leslie et al. (2015: 313) find "no clear genetic evidence of the Danish Viking occupation and control of a large part of England, either in separate UK clusters in that region, or in estimated ancestry profiles, suggesting a relatively limited input of DNA from the Danish Vikings and subsequent mixing with nearby regions".

The third question, that of the nature of the contact situation, is largely ignored by some authors, but we take it to be crucial. We follow van Coetsem (1988, 2000), Winford $(2003,2005)$, and Lucas $(2012,2014)$, who distinguish between two types of transfer according to agentivity. Borrowing occurs under recipientlanguage agentivity: speakers of the language that is to receive the transferred item deliberately import that item into their language. In this case, since the transfer is consciously mediated, prestige may play a major role. Imposition, on the other hand, is the name given by van Coetsem and Winford to transfer that occurs under source language agentivity. Here the most typical scenario is that an unbalanced bilingual, psycholinguistically dominant in the source language, unwittingly imposes items from that language into their L2 (or L3 or L4...) usage, and that this usage becomes the new norm and is transmitted from generation to generation. Prestige, and hence stratal relationships, are barely relevant to such subconsciously-mediated transfer. Evidently, then, if the distinction between borrowing and imposition is on the right track, we need to determine which took place between English and Norse. If it turns out that borrowing is key, then question i) is tremendously important, while ii) is barely relevant, since large numbers of source-language speakers are not required for prestige-driven change (as the later contact situation between English and Anglo-Norman shows). Conversely, if imposition plays the major role, then the question of stratal relationships, i), is relatively unimportant, whereas the proportion of the population who were Norse native speakers, ii), assumes a central role. ${ }^{6}$

Of course, transfer is not the only possible outcome of language contact, as Winford (2005: 376, fn. 3) points out. Lucas (2009) introduces the term restructuring to refer to that type of contact-induced change that is not the result of transfer (see also Lucas 2014: 529). In particular, Trudgill (2011) makes the case that languages may become globally simpler or more complex through contact, again depending on the specifics of the contact situation: long-term co-

6 Van Coetsem's dichotomy is similar to that of Thomason \& Kaufman (1988), who draw a distinction between borrowing and interference through shift. The crucial difference, however, is that Thomason \& Kaufman's typology is ultimately framed in terms of sociolinguistic dominance, while van Coetsem's draws upon psycholinguistic dominance: see Smits 1998, and Winford 2005: 382-385. 
territorial contact involving balanced bilingualism from childhood may lead to complexification, while short-term contact involving L2 acquisition is more likely to lead to simplification.

If we accept this typology of contact, there are four possible types of outcome we might see: a) borrowing; b) imposition; c) complexification; d) simplification. Which we actually see depends on the makeup of the population and on the contact situation. Townend (2002: 207) plausibly suggests that in the history of Anglo-Norse contact first borrowing, then imposition took place. Many authors have also suggested that contact with Norse led to simplification (e.g., Bradley 1904, Jespersen 1938, Görlach 1986, Mitchell 1994, Allen 1997, McWhorter 2002, Townend 2002: 196-201, Fischer 2013); others have attributed the simplification of Middle English morphology to internal factors, or generally remained sceptical with respect to the effect of Norse (Burchfield 1985, Braunmüller 2002, Dance 2012). Trudgill (2011: 53-54) suggests that the contact was long-term and co-territorial, and hence not of the right type to lead to simplification. The switch from stage II to stage III of Jespersen's Cycle has been treated as a case of simplification (cf. Breitbarth 2014 on Middle Low German); however, in view of the ongoing debate in the literature, we will not pursue this line of argument for Norse influence on English. Instead we will examine whether the shift from stage II to III can be interpreted as transfer. ${ }^{7}$

\subsection{Negation and transfer}

If the above considerations are on the right track, then we are very likely to be dealing with imposition (source-language agentivity) rather than borrowing (recipient-language agentivity). Stage III of Jespersen's Cycle is only attested from the Middle English period onwards, and borrowing on prestige grounds is, as discussed, a feature of late Old English instead. Need-based borrowing can also be discounted, since Early Middle English (like every other language) already had a perfectly functional means of marking sentential negation. Moreover, borrowing is usually thought to involve vocabulary rather than syntactic patterns (Winford 2005: 377; though see Lucas 2012: 287-290 on Berber negation as a possible borrowing from Arabic).

Thomason \& Kaufman (1988: 111-112) caution against jumping too readily to substrate-based explanations for interference through shift, and the 'methodological prerequisites' they adduce are relevant for establishing impo-

7 If Trudgill's (2011) characterization of Anglo-Norse contact is correct, we might expect to see complexification in Middle English, for instance transfer of Norse middle voice morphology or suffixal definiteness marking - but there is no evidence of this. The only case Trudgill mentions is the well-studied transfer of third-person pronouns they, them, their, but this could equally well be treated as a case of imposition, and has been (Buccini 1992). 
sition too, mutatis mutandis. First, we must be able to identify a substantial population of speakers who were psycholinguistically dominant in the source language but also used the recipient language. Secondly, we must have information about the structure of the source language; and, thirdly, we must have information about the structure of the target language.

Townend (2002) makes a compelling case, in our view, that Viking Age England displayed societal bilingualism that was 'receptive' in the sense of Braunmüller $(1996,2007)$, i.e., the level of mutual intelligibility between Old English and Norse was such that semicommunication was possible. Subsequently, in the eleventh and twelfth centuries, Norse in England died out, which according to Townend (2002: 201-210) involved a process of imposition through language shift as speakers were increasingly forced to adopt Middle English as a second language. If we accept that, contra Sawyer (1971), a moderate-sized Norsespeaking community existed in England at this time (Loyn 1977, Brooks 1979, Hadley 1997), then Thomason \& Kaufman's (1988) first prerequisite is met.

The second prerequisite is trickier. The varieties of Norse spoken in the British Isles, which in our view constitute the source language, are only attested extremely fragmentarily. Nevertheless, it is a safe inference that these varieties were at stage III of Jespersen's Cycle. Eythórsson (2002: 193-196) describes in detail the history of negation in early Scandinavian. The cognate negator $n e$ is attested in the earliest Old Norse verse texts, the Poetic Edda, but even in these it is restricted in its distribution in a way that suggests that it is an archaism rather than a productive form (Eythórsson 2002: 194). In classical prose, ne is not found. Instead, in early texts, the finite verb suffix -at is the primary negator, along with the adverb eigi in contexts where something other than a finite verb is negated. In all of the modern Scandinavian languages a cognate or similar adverb is used, e.g., Swedish inte, Icelandic ekki, Danish and (Bokmål) Norwegian ikke. Both reflect stage III of Jespersen's Cycle; an illustrative example is given below.

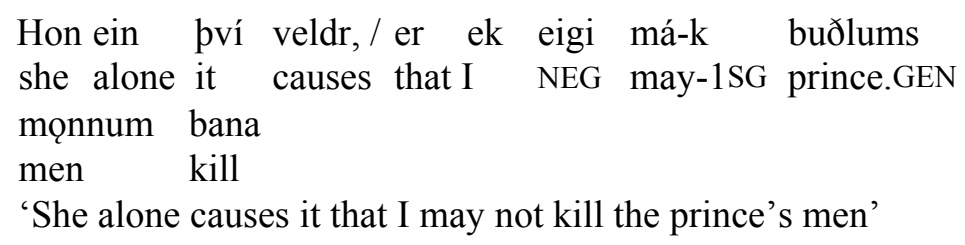

(HHv 26; from Eythórsson 2002: 195)

Norse thus underwent a full Jespersen's Cycle at a pre-textual stage, which is likely to have started before the breakup of Common North Germanic. The geographical distribution of -at is of particular importance to our purposes: it occurs "almost exclusively in Old Icelandic texts" (Eythórsson 2002). In early East Norse there is only a single - questionable - example of - at. In Old Norwegian it is not found in 
literary texts, and is very rare in general, though does occur in a few runic inscriptions. Eythórsson (2002) suggests that it is a West Norse innovation, though one that was subsequently lost in the history of Norwegian. Since the Vikings who raided and ultimately settled in England were Danes and Norwegians, rather than Icelanders, it is likely that the primary negator in British Scandinavian varieties in the eleventh and twelfth centuries was a cognate of eigi and not -at. This gives the right source structure for imposition, with use of not as sole negator on the model of eigi (cf. Ingham 2008: 133).

The third prerequisite is very straightforward. As we have seen, Old English had not progressed to stage III of Jespersen's Cycle, and neither had southern Early Middle English, according to our data. Hence, we have information about the target language before, during and after the change to stage III.

A reasonable objection at this point is that the period we are investigating is too late for Scandinavian influence, given that our earliest texts are from the period 1150-1200. According to Townend (2002), language shift to Middle English occurred in the eleventh and twelfth centuries; similarly, Thomason \& Kaufman (1988: 282) suggest that the shift to English was almost complete by 1100. However, the available material from the north of England during the earlier periods is extremely scanty: it is not until $1300-1350$ that we have texts from Yorkshire or northern Lincolnshire, and in the earliest texts from this area stage III is already the norm. We would therefore suggest that the change took place in this area before the advent of written records. Obviously this must remain a speculation, but it is not inconsistent with the available evidence. An alternative possibility is that stage III was nonexistent in the crucial period before 1300, and that its emergence in the north and east of the English-speaking area is a coincidence; after all, any innovation must emerge somewhere.

\subsection{Discussion of specific texts}

In this section we briefly discuss those texts that display a strikingly high, or strikingly low, rate of stage III use given the general tendencies outlined above.

\subsubsection{Early texts}

The earliest examples of stage III are found in the second continuation of the Peterborough Chronicle (petchront.tag) and the Ormulum (ormt.tag). These three examples are the only ones from the very earliest period, and are reproduced in (14)-(16).

(14) Was it noht suithe lang per-efter pat te king sende efter him Was it NEG very long thereafter that the king sent after him 'it was not long after that that the king sent after him' (petchront.tag; entry for 1132) 
poppæthere fuhtten hi noht nevertheless fought they NEG 'nevertheless they did not fight' (petchront.tag; entry for 1140)

(16) spacc he nohht pipp tunge spoke he NEG with tongue

'he did not speak with his tongue' (ormt.tag)

In terms of the ethnolinguistic areas defined by Thomason \& Kaufman (1988: 270-271), the Chronicle continuation falls within the Norfolk area, and the Ormulum within Fourboroughs. Both are areas which they argue to have been settled early and comparatively extensively by Danish Vikings; in fact, according to Thomason \& Kaufman (1988: 286-287), Norsified English originated in the neighbouring area of Lindsey and spread first to Fourboroughs (950-980) and then to Norfolk (after 980). There is a substantial literature on Norse influence in the Ormulum in particular (Trips 2002, Johannesson 2005). As a result, the only question that might arise is why stage III is not more common than it is in these two texts: only 2 of 8 examples in the Chronicle continuation, and 1 of 24 in the Ormulum. Here it should be noted, however, that other Norse-influenced features are also not used categorically in these texts: see for instance Johannesson (2005) on the variable use of the new third-person plural pronouns in the Ormulum.

\subsubsection{Later texts}

The two texts that show the highest proportion of stage III are late in origin: Hand C of Oxford Merton College MS 248 (merton248t.tag), dating from 1330-40, and the short interlocutory poem Interludium de Clerico et Puella (clericot.tag), dating from circa 1300. In the former, 20 of 22 examples of negation (91\%) are stage III, and in the latter, the single example of negation is stage III. Laing (1997: 107) places the Interludium de Clerico et Puella in the Axholme area of north-western Lincolnshire, which is in the West Riding of Lindsey. She notes that the language of Merton 248 Hand C is very similar, and localizes this also to north-western Lincolnshire. Little can be concluded from the Interludium given that it only contains only one example, but the high proportion of stage III in Merton 248 Hand $\mathrm{C}$ should come as no surprise if, as suggested above, Lindsey was the birthplace of Norsified English. ${ }^{8}$

8 There are three other small texts localized to Lincolnshire which, surprisingly, display only stage I: London Lincoln's Inn MS Hale 135 (hale135t.tag), containing a song in three stanzas, is dated to 1300; Cambridge University Library Ff.VI.15 (tencmFft.tag), containing a ten-line verse on the Ten Commandments, is dated to the first quarter of the fourteenth century; and Oxford Bodleian Library MS Digby 55 (candet3t.tag), containing a copy of Candet Nudatum 
The other texts worthy of comment are the four large post-1300 texts from north of the Humber: the three hands of the Edinburgh Royal College of Physicians MS of Cursor Mundi (edincmat.tag, edincmbt.tag, edincmct.tag), all localized to Yorkshire, as well as the poem A Ballad on the Scottish Wars in British Library MS Cotton Julius A v (scotwart.tag), which is localized to County Durham. In each case, the proportion of stage III is over $50 \%$ - unmatched by any of the other texts except the late Lincolnshire texts mentioned above. It is largely on the basis of the Cursor Mundi that Iyeiri (1992: 78) proposes that the North is more advanced with respect to the change in negation, and our figures match well with hers (see Iyeiri 1992: 55-58), though Iyeiri uses a different, and later, manuscript (British Library Cotton Vespasian A iii).

\section{Conclusion}

In this paper we have conducted a systematic survey of the expression of sentential negation in Early Middle English, focusing in particular on the chronological and geographical distribution of the three stages of Jespersen's Cycle. We have found that northern and eastern texts display more stage III, and earlier, than southern and western texts, and have therefore suggested that Scandinavian influence helped to catalyse the change from stage II to stage III (following Ingham 2008). Our evidence is consistent with the geographical scenario for Scandinavian influence on Middle English presented in Thomason \& Kaufman (1988: 284-299), according to which the Norsified English "package" originated in Lindsey (present-day northern Lincolnshire) and radiated out from there. In terms of the typology of language contact effects, we have suggested that the most likely scenario is that stage III is a case of imposition, in the terms of van Coetsem (1988) and Winford (2005); Townend (2002) presents a number of other likely impositions from Norse.

We cannot, of course, be certain that contact was involved: a purely endogenous development remains a possibility, especially given the late attestation of texts from the Danelaw area. Beyond the suggestive geographical distribution, however, we can be confident that a) there was a substantial population of Scandinavian speakers in a situation likely to lead to imposition in the 11th century, b) earlier Old and Middle English had not progressed to stage III of Jespersen's Cycle, and c) earlier Norse (at least in its attested, non-Insular varieties) had. The data we have presented should allow the reader to evaluate this and other hypotheses and draw their own conclusions.

Pectus in Latin and English as well as five short couplets, is dated to the second half of the thirteenth century. In each case, however, we are dealing with only a single example of negation. 


\section{REFERENCES}

Allen, Cynthia. 1997. Middle English case loss and the 'creolization' hypothesis. English Language and Linguistics 1(1). 63-89. DOI: 10.1017/S1360674300000368

Bech, Kristin \& George Walkden. 2016. English is (still) a West Germanic language. Nordic Journal of Linguistics 39(1). 65-100. DOI: 10.1017/S0332586515000219

Bradley, Henry. 1904. The making of English. London: Macmillan.

Braunmüller, Kurt. 1996. Forms of language contact in the area of the Hanseatic League: Dialect contact phenomena and semicommunication. Nordic Journal of Linguistics 19(2). 141154. DOI: $10.1017 / \mathrm{S} 033258650000336 \mathrm{X}$

Braunmüller, Kurt. 2002. Language contact during the Old Nordic period I: Within the British Isles, Frisia and the Hanseatic League. In Oscar Bandle, Kurt Braunmüller, Ernst Håkon Jahr, Allan Karker, Hans-Peter Naumann \& Ulf Teleman (eds.), The Nordic languages: An international handbook of the history of the North Germanic languages, vol. 1, 10281039. Berlin: de Gruyter. DOI: 10.1515/9783110197051-114

Braunmüller, Kurt. 2007. Receptive multilingualism in Northern Europe in the Middle Ages: A description of a scenario. In Jan D. ten Thije \& Ludger Zeevaert (eds.), Receptive multilingualism: Linguistic analyses, language policies and didactic concepts, 25-47. Amsterdam: John Benjamins. DOI: 10.1075/hsm.6.04bra

Breitbarth, Anne. 2014. Dialect contact and the speed of Jespersen's Cycle in Middle Low German. Taal en Tongval 66. 1-20. DOI: 10.5117/TET2014.1.BREI

Brooks, N. P. 1979. England in the ninth century: The crucible of defeat. Transactions of the Royal Historical Society 29. 1-20. DOI: 10.2307/3679110

Buccini, Anthony F. 1992. Southern Middle English hise and the question of pronominal transfer in language contact. In Rosina Lippi-Green (ed.), Recent developments in Germanic linguistics, 11-32. Amsterdam: John Benjamins. DOI: 10.1075/cilt.93.04buc

Burchfield, Robert W. 1985. The English language. Oxford: Oxford University Press.

Coetsem, Frans, van. 1988. Loan phonology and the two transfer types in language contact. Dordrecht: Foris.

Coetsem, Frans, van. 2000. A general and unified theory of the transmission process in language contact. Heidelberg: Carl Winter.

Dahl, Östen. 1979. Typology of sentence negation. Linguistics 17(1-2). 79-106. DOI: 10.1515/ling.1979.17.1-2.79

Dance, Richard. 2012. English in contact: Norse. In Alexander Bergs \& Laurel J. Brinton (eds.), English historical linguistics: An international handbook, vol. 2, 1724-1737. Berlin: de Gruyter. DOI: 10.1515/9783110251609.1724

Emonds, Joseph \& Jan Terje Faarlund. 2014. English: The language of the Vikings. Olomouc: Palacký University Press.

Eythórsson, Thórhallur. 2002. Negation in C: The syntax of negated verbs in Old Norse. Nordic Journal of Linguistics 25(2). 190-224. DOI: 10.1080/033258602321093364

Fischer, Olga. 2013. The role of contact in English syntactic change in the Old and Middle English periods. In Daniel Schreier \& Marianne Hundt (eds.), English as a contact language, 19-40. Cambridge: Cambridge University Press. DOI: 10.1017/CBO9780511740060.002

Frisch, Stefan. 1997. The change in negation in Middle English: A NEGP licensing account. Lingua 101(1-2). 21-64. DOI: 10.1016/S0024-3841(96)00018-6 
Görlach, Manfred. 1986. Middle English - a creole? In Dieter Kastovsky \& Aleksander Szwedek (eds.), Linguistics across historical and geographical boundaries, 329-344. Berlin: Mouton de Gruyter. DOI: 10.1515/9783110856132.329

Hadley, Dawn. 1997. "And they proceeded to plough and to support themselves”: The Scandinavian settlement of England. Anglo-Norman England 19. 69-96.

Hock, Hans Henrich. 1986. Principles of historical linguistics. Berlin: Mouton de Gruyter.

Hogg, Richard M. 2004. The spread of negative contraction in early English. In Anne Curzan \& Kimberley Emmons (eds.), Studies in the history of the English language II: Unfolding conversations, 459-482. Berlin: Mouton de Gruyter. DOI: $10.1515 / 9783110897661.459$

Holman, Katherine. 2001. Defining the Danelaw. In James Graham-Campbell, Richard Hall, Judith Jesch \& David N. Parsons (eds.), Vikings and the Danelaw: Select papers from the proceedings of the Thirteenth Viking Congress, 1-11. Oxford: Oxbow Books.

Ingham, Richard. 2006. Negative concord and the loss of the negative particle ne in Late Middle English. Studia Anglica Posnaniensia 42. 77-97.

Ingham, Richard. 2008. Contact with Scandinavian and Late Middle English negative concord. Studia Anglica Posnaniensia 44. 121-137.

Ingham, Richard. 2013. Negation in the history of English. In David Willis, Christopher Lucas \& Anne Breitbarth (eds.), The history of negation in the languages of Europe and the Mediterranean. Vol. 1: Case studies, 119-150. Oxford: Oxford University Press. DOI: 10.1093/acprof:oso/9780199602537.003.0004

Iyeiri, Yoko. 1992. Negative constructions in selected Middle English verse texts. Ph.D. dissertation, University of St Andrews.

Iyeiri, Yoko. 2001. Negative constructions in Middle English. Fukuoka: Kyushu University Press. Jack, George B. 1978. Negation in later Middle English prose. Archivum Linguisticum 9. 58-72.

Jespersen, Otto. 1917. Negation in English and other languages. Copenhagen: A. F. Høst.

Jespersen, Otto. 1938. Growth and structure of the English language. Oxford: Blackwell.

Johannesson, Nils-Lennart. 2005. Old English versus Old Norse vocabulary in the Ormulum: The choice of third person plural personal pronouns. Ms., Stockholm University. https://www.orrmulum.net/ormproj/info/heore97_rev.pdf

Kastovsky, Dieter. 2006. Vocabulary. In Richard Hogg \& David Denison (eds.), A history of the English language, 199-270. Cambridge: Cambridge University Press.

Kroch, Anthony \& Ann Taylor. 2000. Penn-Helsinki Parsed Corpus of Middle English Prose. 2nd edition. https://www.ling.upenn.edu/hist-corpora/PPCME2-RELEASE-3/index.html

Laing, Margaret. 1997. A fourteenth-century sermon on the number seven in Merton College, Oxford, MS 248. Neuphilologische Mitteilungen 98(2). 99-134.

Laing, Margaret. 2002. Corpus-provoked questions about negation in early Middle English. Language Sciences 24(3-4). 297-321. DOI: 10.1016/S0388-0001(01)00035-3

Laing, Margaret. 2013-. A linguistic atlas of Early Middle English. Version 3.2. https://www.lel.ed.ac.uk/ihd/laeme2/laeme2_framesZ.html

Laing, Margaret \& Roger Lass. 2008-. A linguistic atlas of Early Middle English. Introduction. https://www.lel.ed.ac.uk/ihd/laeme2/laeme_intro_ch4.html

Leslie, Stephen, Bruce Winney, Garrett Hellenthal, Dan Davison, Abdelhamid Boumertit, Tammy Day, Katarzyna Hutnik, Ellen C. Royrvik, Barry Cunliffe, Wellcome Trust Case Consortium 2, International Multiple Sclerosis Genetics Consortium, Daniel J. Lawson, Daniel Fallush, Colin Freeman, Matti Pirinen, Simon Myers, Mark Robinson, 
Peter Donnelly \& Walter Bodmer. 2015. The fine-scale genetic structure of the British population. Nature 519. 309-314. DOI: 10.1038/nature14230

Levin, Samuel R. 1958. Negative contraction: An Old and Middle English dialect criterion. The Journal of English and Germanic Philology 57(3). 492-501.

Loyn, Henry R. 1977. The Vikings in Britain. New York: St. Martin's Press.

Lucas, Christopher. 2009. The development of negation in Arabic and Afro-Asiatic. Ph.D. dissertation, University of Cambridge.

Lucas, Christopher. 2012. Contact-induced grammatical change: Towards an explicit account. Diachronica 29(3). 275-300. DOI: 10.1075/dia.29.3.01luc

Lucas, Christopher. 2014. Contact-induced language change. In Claire Bowern \& Bethwyn Evans (eds.), The Routledge handbook of historical linguistics, 519-536. London: Routledge. DOI: $10.4324 / 9781315794013 . \operatorname{ch} 24$

Lutz, Angelika. 2012. Norse influence on English in the light of general contact linguistics. In Irén Hegedüs \& Alexandra Fodor (eds.), English historical linguistics 2010: Selected papers from the Sixteenth International Conference on English Historical Linguistics (ICEHL 16), Pécs, 23-27 August 2010, 15-41. Amsterdam: John Benjamins. DOI: 10.1075/cilt.325.01lut

Lutz, Angelika. 2013. Language contact and prestige. Anglia 131(4). 562-590. DOI: 10.1515/anglia-2013-0065

McIntosh, Angus, Michael L. Samuels \& Michael Benskin. 1986. A linguistic atlas of Late Mediaeval English. Aberdeen: Aberdeen University Press.

McWhorter, John. 2002. What happened to English? Diachronica 19(2). 217-272. DOI: 10.1075/dia.19.2.02wha

Miller, D. Gary. 2012. External influences on English: From its beginnings to the Renaissance. Oxford: Oxford University Press. DOI: 10.1093/acprof:oso/9780199654260.001.0001

Mitchell, Bruce. 1994. The Englishness of Old English. In Malcolm Godden, Douglas Gray \& Terry Hoad (eds.), From Anglo-Saxon to Early Middle English: Studies presented to E. G. Stanley, 163-181. Oxford: Clarendon.

Peters, Hans. 1981. Zum skandinavischen Lehngut im Altenglischen. Sprachwissenschaft 6. 85-124.

Pons-Sanz, Sara. 2007. Norse-derived vocabulary in late Old English texts: Wulfstan's works, a case study. Amsterdam: John Benjamins. DOI: 10.1075/nss.22

Pons-Sanz, Sara. 2013. The lexical effects of Anglo-Scandinavian linguistic contact on Old English. Turnhout: Brepols.

Poussa, Patricia. 1982. The evolution of Early Standard English: The creolization hypothesis. Studia Anglica Posnaniensia 14. 69-85.

Sawyer, Peter H. 1971. The age of the Vikings. (2nd edn.) London: Arnold.

Smits, Caroline. 1998. Two models for the study of language contact: A psycho-linguistic perspective versus a socio-cultural perspective. In Monika S. Schmid, Jennifer R. Austin \& Dieter Stein (eds.), Historical linguistics, 1997: Selected papers from the 13th International Conference on Historical Linguistics, Düsseldorf, 10-17 August 1997, 377-391. Amsterdam: John Benjamins. DOI: 10.1075/cilt.164.24smi

Studer-Joho, Nicole. 2014. Diffusion and change in Early Middle English: Methodological and theoretical implications from the LAEME corpus of tagged texts. Tübingen: Francke Verlag.

Sykes, Bryan. 2006. Blood of the Isles: Exploring the genetic roots of our tribal history. London: Bantam. 
Thomason, Sarah Grey \& Terrence Kaufman. 1988. Language contact, creolization, and genetic linguistics. Los Angeles, CA: University of California Press.

Townend, Matthew. 2002. Language and history in Viking Age England: Linguistic relations between speakers of Old Norse and Old English. Turnhout: Brepols.

Trips, Carola. 2002. From OV to VO in Early Middle English. Amsterdam: John Benjamins. DOI: 10.1075/la.60

Trudgill, Peter. 2011. Sociolinguistic typology: Social determinants of linguistic complexity. Oxford: Oxford University Press.

Van Bergen, Linda. 2008. Negative contraction and Old English dialects: Evidence from glosses and prose. Part I. Neuphilologische Mitteilungen 109(3). 275-312.

Wallage, Phillip. 2005. Negation in early English: Parametric variation and grammatical competition. Ph.D. dissertation, University of York.

Wallage, Phillip. 2008. Jespersen's Cycle in Middle English: Parametric variation and grammatical competition. Lingua 118(5). 643-674. DOI: 10.1016/j.lingua.2007.09.001

Wallage, Phillip. 2013. Functional differentiation and grammatical competition in the English Jespersen Cycle. Journal of Historical Syntax 2(1). 1-25.

Winford, Donald. 2003. An introduction to contact linguistics. Oxford: Wiley-Blackwell.

Winford, Donald. 2005. Contact-induced changes: Classification and processes. Diachronica 22(2). 373-427. DOI: 10.1075/dia.22.2.05win 


\section{A Results by text}

\begin{tabular}{|c|c|c|c|c|c|c|c|c|c|}
\hline \multicolumn{3}{|l|}{ Text details } & \multicolumn{2}{|c|}{ Stage I } & \multicolumn{2}{|c|}{ Stage II } & \multicolumn{2}{|c|}{ Stage III } & \multirow{2}{*}{$\begin{array}{c}\text { Total } \\
\mathrm{N} \\
\end{array}$} \\
\hline Text & Date & Period & $\mathrm{N}$ & $\%$ & $\mathrm{~N}$ & $\%$ & $\mathrm{~N}$ & $\%$ & \\
\hline petchront.tag & 1154 & 1150-1199 & 4 & 50 & 2 & 25 & 2 & 25 & 8 \\
\hline ormt.tag & 1188 & 1150-1199 & 6 & 25 & 17 & 71 & 1 & 4 & 24 \\
\hline trhomAt.tag & 1188 & 1150-1199 & 15 & 65 & 8 & 35 & 0 & 0 & 23 \\
\hline trhomBt.tag & 1188 & $1150-1199$ & 63 & 64 & 35 & 36 & 0 & 0 & 98 \\
\hline trinpmt.tag & 1188 & $1150-1199$ & 13 & 76 & 4 & 24 & 0 & 0 & 17 \\
\hline worcsermont.tag & 1188 & $1150-1199$ & 1 & 33 & 2 & 67 & 0 & 0 & 3 \\
\hline lamhomA1t.tag & 1200 & $1200-1249$ & 55 & 67 & 27 & 33 & 0 & 0 & 82 \\
\hline lamhomA2t.tag & 1200 & $1200-1249$ & 14 & 42 & 19 & 58 & 0 & 0 & 33 \\
\hline lampmt.tag & 1200 & $1200-1249$ & 11 & 85 & 2 & 15 & 0 & 0 & 13 \\
\hline digpmt.tag & 1213 & $1200-1249$ & 15 & 83 & 3 & 17 & 0 & 0 & 18 \\
\hline lamursnt.tag & 1213 & $1200-1249$ & 7 & 100 & 0 & 0 & 0 & 0 & 7 \\
\hline vvat.tag & 1213 & $1200-1249$ & 58 & 55 & 48 & 45 & 0 & 0 & 106 \\
\hline vvbt.tag & 1213 & $1200-1249$ & 20 & 71 & 8 & 29 & 0 & 0 & 28 \\
\hline vvcorrt.tag & 1213 & $1200-1249$ & 0 & 0 & 1 & 100 & 0 & 0 & 1 \\
\hline wintneyt.tag & 1213 & $1200-1249$ & 8 & 100 & 0 & 0 & 0 & 0 & 8 \\
\hline maidsdwct.tag & 1225 & $1200-1249$ & 2 & 100 & 0 & 0 & 0 & 0 & 2 \\
\hline maidspat.tag & 1225 & $1200-1249$ & 9 & 69 & 2 & 15 & 2 & 15 & 13 \\
\hline prisprayt.tag & 1225 & $1200-1249$ & 1 & 50 & 1 & 50 & 0 & 0 & 2 \\
\hline royalkgat.tag & 1225 & $1200-1249$ & 17 & 40 & 26 & 60 & 0 & 0 & 43 \\
\hline royalkgbt.tag & 1225 & $1200-1249$ & 11 & 61 & 7 & 39 & 0 & 0 & 18 \\
\hline royalkgct.tag & 1225 & $1200-1249$ & 10 & 53 & 9 & 47 & 0 & 0 & 19 \\
\hline worcthfragst.tag & 1225 & $1200-1249$ & 4 & 80 & 1 & 20 & 0 & 0 & 5 \\
\hline worcthgrglt.tag & 1225 & $1200-1249$ & 30 & 77 & 9 & 23 & 0 & 0 & 39 \\
\hline cleoarat.tag & 1233 & $1200-1249$ & 28 & 43 & 36 & 55 & 1 & 2 & 65 \\
\hline hat26tct.tag & 1234 & $1200-1249$ & 1 & 100 & 0 & 0 & 0 & 0 & 1 \\
\hline bod34t.tag & 1238 & $1200-1249$ & 17 & 40 & 25 & 60 & 0 & 0 & 42 \\
\hline corpart.tag & 1238 & $1200-1249$ & 32 & 48 & 32 & 48 & 2 & 3 & 66 \\
\hline neroart.tag & 1238 & $1200-1249$ & 26 & 43 & 35 & 57 & 0 & 0 & 61 \\
\hline nerowgt.tag & 1238 & $1200-1249$ & 12 & 71 & 4 & 24 & 1 & 6 & 17 \\
\hline wellsbt.tag & 1240 & $1200-1249$ & 1 & 100 & 0 & 0 & 0 & 0 & 1 \\
\hline cleoarbt.tag & 1245 & $1200-1249$ & 1 & 100 & 0 & 0 & 0 & 0 & 1 \\
\hline titusart.tag & 1245 & $1200-1249$ & 29 & 47 & 31 & 50 & 2 & 3 & 62 \\
\hline tituswoht.tag & 1245 & $1200-1249$ & 11 & 69 & 4 & 25 & 1 & 6 & 16 \\
\hline caiusart.tag & 1263 & $1250-1299$ & 12 & 43 & 14 & 50 & 2 & 7 & 28 \\
\hline iacobt.tag & 1263 & $1250-1299$ & 9 & 75 & 0 & 0 & 3 & 25 & 12 \\
\hline
\end{tabular}




\begin{tabular}{|c|c|c|c|c|c|c|c|c|c|}
\hline layamonAat.tag & 1263 & $1250-1299$ & 10 & 59 & 7 & 41 & 0 & 0 & 17 \\
\hline layamonAbt.tag & 1263 & $1250-1299$ & 7 & 50 & 7 & 50 & 0 & 0 & 14 \\
\hline layamonBOt.tag & 1263 & $1250-1299$ & 9 & 60 & 5 & 33 & 1 & 7 & 15 \\
\hline tanner169t.tag & 1263 & $1250-1299$ & 0 & 0 & 1 & 100 & 0 & 0 & 1 \\
\hline tr323at.tag & 1263 & $1250-1299$ & 7 & 50 & 7 & 50 & 0 & 0 & 14 \\
\hline tr323bt.tag & 1263 & $1250-1299$ & 10 & 56 & 6 & 33 & 2 & 11 & 18 \\
\hline tr323ct.tag & 1263 & $1250-1299$ & 4 & 57 & 1 & 14 & 2 & 29 & 7 \\
\hline tr323dt.tag & 1263 & $1250-1299$ & 16 & 70 & 5 & 22 & 2 & 9 & 23 \\
\hline trincleoDt.tag & 1263 & $1250-1299$ & 7 & 64 & 1 & 9 & 3 & 27 & 11 \\
\hline candet 3 t.tag & 1275 & $1250-1299$ & 1 & 100 & 0 & 0 & 0 & 0 & 1 \\
\hline lam499t.tag & 1275 & $1250-1299$ & 1 & 100 & 0 & 0 & 0 & 0 & 1 \\
\hline vitelld3t.tag & 1275 & $1250-1299$ & 5 & 56 & 4 & 44 & 0 & 0 & 9 \\
\hline digby 86 mapt.tag & 1277 & $1250-1299$ & 31 & 52 & 28 & 47 & 1 & 2 & 60 \\
\hline adde6at.tag & 1288 & $1250-1299$ & 2 & 50 & 2 & 50 & 0 & 0 & 4 \\
\hline adde6bt.tag & 1288 & $1250-1299$ & 4 & 33 & 3 & 25 & 5 & 42 & 12 \\
\hline arundel248t.tag & 1288 & $1250-1299$ & 1 & 20 & 2 & 40 & 2 & 40 & 5 \\
\hline bodley26t.tag & 1288 & 1250-1299 & 1 & 50 & 1 & 50 & 0 & 0 & 2 \\
\hline ccco59t.tag & 1288 & $1250-1299$ & 2 & 100 & 0 & 0 & 0 & 0 & 2 \\
\hline cotowlat.tag & 1288 & $1250-1299$ & 31 & 74 & 11 & 26 & 0 & 0 & 42 \\
\hline cotowlbt.tag & 1288 & $1250-1299$ & 15 & 56 & 12 & 44 & 0 & 0 & 27 \\
\hline jes29t.tag & 1288 & $1250-1299$ & 64 & 67 & 30 & 32 & 1 & 1 & 95 \\
\hline laud471kst.tag & 1288 & $1250-1299$ & 5 & 50 & 5 & 50 & 0 & 0 & 10 \\
\hline royal2f8t.tag & 1288 & $1250-1299$ & 3 & 75 & 1 & 25 & 0 & 0 & 4 \\
\hline buryFft.tag & 1299 & 1250-1299 & 8 & 100 & 0 & 0 & 0 & 0 & 8 \\
\hline clericot.tag & 1300 & $1300-1350$ & 0 & 0 & 0 & 0 & 1 & 100 & 1 \\
\hline dulwicht.tag & 1300 & $1300-1350$ & 6 & 35 & 8 & 47 & 3 & 18 & 17 \\
\hline hale135t.tag & 1300 & $1300-1350$ & 1 & 100 & 0 & 0 & 0 & 0 & 1 \\
\hline corp145selt.tag & 1313 & $1300-1350$ & 50 & 43 & 64 & 55 & 2 & 2 & 116 \\
\hline emmanuel27t.tag & 1313 & $1300-1350$ & 0 & 0 & 2 & 50 & 2 & 50 & 4 \\
\hline genexodt.tag & 1313 & $1300-1350$ & 17 & 40 & 13 & 30 & 13 & 30 & 43 \\
\hline havelokt.tag & 1313 & $1300-1350$ & 46 & 48 & 26 & 27 & 23 & 24 & 95 \\
\hline tencmFft.tag & 1313 & $1300-1350$ & 1 & 100 & 0 & 0 & 0 & 0 & 1 \\
\hline beverleyt.tag & 1325 & $1300-1350$ & 1 & 100 & 0 & 0 & 0 & 0 & 1 \\
\hline edincmat.tag & 1325 & $1300-1350$ & 20 & 24 & 17 & 21 & 45 & 55 & 82 \\
\hline edincmbt.tag & 1325 & $1300-1350$ & 11 & 11 & 11 & 11 & 78 & 78 & 100 \\
\hline edincmct.tag & 1325 & $1300-1350$ & 10 & 14 & 23 & 32 & 40 & 55 & 73 \\
\hline scotwart.tag & 1325 & $1300-1350$ & 3 & 27 & 0 & 0 & 8 & 73 & 11 \\
\hline merton248t.tag & 1338 & $1300-1350$ & 1 & 5 & 1 & 5 & 20 & 91 & 22 \\
\hline ayenbitet.tag & 1340 & $1300-1350$ & 77 & 40 & 114 & 59 & 3 & 2 & 194 \\
\hline
\end{tabular}

